\title{
Correction to: The effect of ultrasound hyperthermia with gold nanoparticles on retinoblastoma Y79 cells
}

\author{
Somayeh Moradi ${ }^{1}$ Manijhe Mokhtari-Dizaji ${ }^{1} \cdot$ Fariba Ghassemi $^{2} \cdot$ Shahab Sheibani $^{3} \cdot$ Fahimeh Asadi Amoli $^{4}$
}

Published online: 4 June 2020

(C) Springer Nature Switzerland AG 2020

\section{Correction to: Gold Bulletin} https://doi.org/10.1007/s13404-020-00279-w

The publication of this article unfortunately contained a mistake. The given name of the corresponding author was not correct. It should be Manijhe instead of Manijeh.

The online version of the original article can be found at https://doi.org/ 10.1007/s13404-020-00279-w

Manijhe Mokhtari-Dizaji

mokhtarm@modares.ac.ir

1 Department of Medical Physics, Faculty of Medical Sciences, Tarbiat Modares University, Tehran, Iran

2 Eye Research Center, Farabi Eye Hospital, Tehran University of Medical Sciences, Tehran, Iran

3 Radiation Application Research School, Nuclear Science and Technology Research Institute, Tehran, Iran

4 Department of Pathology, Eye Research Center, Farabi Eye Hospital, Tehran University of Medical Sciences, Tehran, Iran 